Revista de la red interuniversitaria de estudios sobre las literaturas rioplatenses contemporáneas en Francia

\title{
Una propuesta para el próximo milenio
}

\section{Ricardo Piglia}

URL: http://journals.openedition.org/lirico/1101

DOI: $10.4000 /$ lirico.1101

ISSN: 2262-8339

Editor

Réseau interuniversitaire d'étude des littératures contemporaines du Río de la Plata

Referencia electrónica

Ricardo Piglia, « Una propuesta para el próximo milenio », Cuadernos LIRICO [En línea], 9 | 2013, Puesto en línea el 01 septiembre 2013, consultado el 05 mayo 2019. URL : http://journals.openedition.org/ lirico/1101 ; DOl : 10.4000/lirico.1101

Este documento fue generado automáticamente el 5 mayo 2019.

\section{(c) $(\mathbb{1 0} \Theta \Theta$}

Cuadernos LIRICO está distribuido bajo una Licencia Creative Commons Atribución-NoComercialSinDerivar 4.0 Internacional. 


\title{
Una propuesta para el próximo milenio
}

\author{
Ricardo Piglia
}

In memoriam Anita Barrenechea, que me enseñó a

leer todos los detalles

En 1985 el escritor italiano Italo Calvino preparó una serie de conferencias para ser leídas en Harvard con el título de Seis propuestas para el próximo milenio. Allí, enumeraba algunos de los procedimientos de la literatura que era necesario conservar o que sería deseable que persistieran en el futuro. Y para Calvino esos valores eran la levedad, la rapidez, la exactitud, la visibilidad, la multiplicidad; en realidad las seis propuestas previstas, quedaron reducidas a cinco, que son las que se encontraron escritas después de la muerte de Calvino.

2 Pensé que quizá podríamos imaginar la propuesta que falta. ¿Cual sería la sexta proposición no escrita para el próximo milenio ? ¿Y cual sería esa propuesta pensada desde Buenos Aires, desde este suburbio del mundo? ¿Cómo se verían el futuro de la literatura o la literatura del futuro, desde el margen, en la periferia de las tradiciones centrales, mirando al sesgo.

3 El intento de imaginar qué valor podría persistir es, por supuesto, una ficción especulativa, una suerte de versión utópica de "Pierre Menard, autor del Quijote". No tanto cómo reescribiríamos literalmente una obra maestra del pasado sino como escribiríamos imaginariamente la obra maestra futura. O para decirlo así, cómo describiríamos las posibilidades de una literatura futura, de una literatura potencial. Imaginar las condiciones de la literatura en el porvenir supone también por supuesto inferir la realidad que esa literatura postula. La literatura imagina realidades posibles, dice cómo decir bien el porvenir, cómo imaginar una vida posible, una vida alternativa.

4 Propuesta entonces como consigna, puntos de partida de un debate futuro o si se prefiere de un debate sobre el futuro, emprendido desde otro lugar. Tal vez el hecho de escribir desde la Argentina nos enfrenta con los límites de la literatura y nos permite reflexionar sobre los límites. La experiencia del horror puro de la represión clandestina, que a menudo parece estar más allá de las palabras, quizá define nuestro uso del lenguaje y por lo tanto el futuro y el sentido. Hay un punto extremo, un lugar -digamos - al que parece 
imposible acercarse con la literatura. Como si el lenguaje tuviera un borde, como si el lenguaje fuera un territorio con una frontera, después del cual está el silencio. ¿Cómo narrar el horror? Cómo trasmitir la experiencia del horror y no sólo informar sobre él ? Muchos escritores en el siglo XX han enfrentado esta cuestión : Primo Levi, Ana Ajmatova, Paul Celan. La experiencia de los campos de concentración, la experiencia del Gulag, la experiencia del genocidio. La literatura prueba que hay acontecimientos que son muy difíciles, casi imposibles, de trasmitir, que suponen una relación nueva con el lenguaje de los límites.

5 Para empezar a plantearnos la cuestión quisiera referime a algunos escritos de Rodolfo Walsh e incluso a su figura que para muchos de nosotros es una síntesis de la tradición de la política hoy en la literatura argentina, por un lado un gran escritor y al mismo tiempo alguien que como muchos otros en nuestra historia, llevó al límite la noción de responsabilidad civil del intelectual.

6 Walsh comenzó escribiendo cuentos policiales a la Borges y escribió uno de los grandes textos de literatura documental de Hispanoamérica: Operación Masacre (1956) y paralelamente publicó en los años 60 una extraordinaria serie de relatos cortos (en sus libros Los oficios terrestres y Un kilo de oro) y por fin, desde la resistencia clandestina a la dictadura militar, escribió y distribuyó el 24 de marzo de 1977 su "Carta abierta de un escritor a la Junta Militar" que es una diatriba concisa y lúcida y una denuncia de los crímenes del estado terrorista. Walsh fue asesinado al día siguiente en una emboscada que le tendió un grupo de tareas de la Escuela de Mecánica de la Armada. Su casa fue allanada y sus manuscritos fueron secuestrados y destruidos por la dictadura.

7 Quisiera analizar el modo que tiene un escritor, en condiciones de clandestinidad y de persecución, de contar una experiencia extrema y trasmitir un acontecimiento que parece de antemano imposible de narrar. Quisiera recordar el modo en que Walsh cuenta la muerte de su hija Vicky, -una joven guerrillera que muere en un enfrentamiento con la represión militar- y escribe lo que se conoce como "Carta a Vicky", que circuló clandestinamente en 1976.

8 Luego de reconstruir el momento en que se entera de la muerte y el gesto que acompaña esa revelación ("Escuché tu nombre mal pronunciado, y tardé un segundo en asimilarlo. Maquinalmente empecé a santiguarme como cuando era chico"), Walsh escribe : “Anoche tuve una pesadilla torrencial en la que había una columna de fuego, poderosa, pero contenida en sus límites que brotaba de alguna profundidad". Una pesadilla casi sin contenido, condensada en una imagen casi abstracta. Y después escribe : "Hoy en el tren un hombre decía "Sufro mucho, quisiera acostarme a dormir y despertarme dentro de un año". Y concluye Walsh : "Hablaba por él pero también por mí". Quisiera detenerme en ese movimiento, ese desplazamiento, darle la palabra al otro que habla de su dolor, un desconocido en un tren, que dice "Sufro, quisiera despertarme dentro de un año". Es casi una elipsis, una pequeña toma de distancia respecto a lo que está tratando de decir, un deslizamiento de la enunciación, alguien habla por él y expresa el dolor de un modo sobrio y directo y muy conmovedor. Hace un pequeñísimo movimiento pronominal para lograr que alguien por él pueda decir lo que él quiere decir. Una lección de estilo, un intento de condensar el cristal de la experiencia.

9 El mismo desplazamiento utiliza Walsh en el texto donde cuenta las circunstancias en las que muere Vicky, "Carta a mis amigos". Narra el cerco militar a la casa, la resistencia, el combate. Y para describir lo que ha sucedido nuevamente le da la voz a otro. Dice : "Me ha llegado el testimonio de uno de esos hombres, un conscripto". Y transcribe el relato del 
que estaba ahí sitiando el lugar. "El combate duró más de una hora y media. Un hombre y una muchacha tiraban desde arriba. Nos llamó la atención la muchacha, porque cada vez que tiraba una ráfaga y nosotros nos zambullíamos, ella se reía". La risa está ahí, narrada por otro, la extrema juventud, el asombro, todo se condensa. La impersonalidad del relato y la admiración de sus propios enemigos, refuerzan el heroísmo de la escena. Los que van a matarla son los primeros que reconocen su valor, en la mejor tradición de la épica. Al mismo tiempo el testigo certifica la verdad y permite al que escribe ver la escena y narrarla, como si fuera otro. Igual que en el caso del hombre en el tren, acá también hace un desplazamiento y le da la voz a otro que condensa lo que quiere decir.

Quizá ese soldado nunca existió, como quizá nunca existió ese hombre en el tren, lo que importa es que están ahí para poder narrar el punto ciego de la experiencia. Puede entenderse como una ficción, tiene por supuesto la forma de una ficción destinada a decir la verdad, el relato se desplaza hacia una situación concreta donde hay otro, inolvidable, que permite fijar y hacer visible lo que se quiere decir.

Es algo que el propio Walsh había hecho muchos años antes, en 1964, cuando trataba de contar el modo en que había sido arrastrado por la historia. En el prólogo a la tercera edición de Operación masacre Walsh narra una escena inicial, narra digamos su ficción del origen, y condensa así la entrada de la historia y de la política en su vida. Está en un bar en la ciudad de La Plata, un bar al que va siempre a hablar de literatura y a jugar al ajedrez y una noche de 1956 se oye un tiroteo, hay corridas, un grupo de peronistas y de militares rebeldes asalta al comando de la segunda división del ejército, es el comienzo de la fracasada revolución de Valle que va a concluir en la represión clandestina y en los fusilamientos de José León Suárez sobre los que Walsh realizará la denuncia en Operación Masacre. .

Esa noche Walsh sale del bar con los otros parroquianos, corre por las calles arboladas y por fin se refugia en su casa que está cerca del lugar de los enfrentamientos. Y entonces narra. "Tampoco olvido que, pegado a la persiana, oí morir a un conscripto en la calle y ese hombre no dijo : ¡Viva la patria!, sino que dijo : No me dejen solo, hijos de puta”. Una lección de historia pero también otra lección de estilo. Una vez más el desplazamiento que condensa un sentido múltiple en una sola escena y en una voz. Este otro conscripto que está ahí aterrado, que está por morir, es el que cristaliza una red múltiple de significaciones. Un movimiento que es interno al relato, otra elipsis, que desplaza hacia el otro la experiencia de la historia.

Walsh hace ver de qué manera podemos mostrar lo que parece casi imposible de decir. La literatura sería el lugar en el que siempre es otro el que viene a decir. "Yo soy otro", como decía Rimbaud. El estilo seria ese movimiento hacia otra enunciación, una toma de distancia respecto a la palabra propia. Me parece entonces que podríamos imaginar que hay una sexta propuesta. A la que yo llamaría, el deslizamiento, el desplazamiento, el cambio de lugar. Salir del centro, dejar que el lenguaje hable también en el borde, en lo que se oye, en lo que llega de otro.

14 En el año 2222, cuando el nombre de todos los autores se haya perdido y la literatura sea intemporal y sea anónima, esta pequeña propuesta sobre el desplazamiento y la distancia, será, tal vez, un apéndice o una intercalación apócrifa en un web.site llamado Las seis propuestas que para ese entonces serán leídas como si fueran consignas en un antiguo manual de estrategia usado para sobrevivir en tiempos difíciles. 


\section{RESÚMENES}

Inspirándose en las Seis propuestas para el próximo milenio de Ítalo Calvino, el ensayo plantea una adicional. Analiza para ello la manera en que Rodolfo Walsh trasmite un acontecimiento que parece de antemano imposible de narrar, desplazando la fuente de la enunciación y poniendo la experiencia en la voz de otro. El estilo de un escritor sería ese movimiento hacia otra enunciación. La nueva propuesta para la literatura del futuro reivindica entonces el doble procedimiento de desplazamiento y de distanciación de la experiencia.

Cet essai postule une proposition supplémentaire des six que Calvino imagina pour le prochain millénaire. Á cette fin il analyse les modalités discursives employées par Rodolfo Walsh lorsqu'il s'agit de transmettre un fait qui semble d'emblée impossible à raconter, à savoir le déplacement de la source d'énonciation et la délégation de l'expérience à la voix d'un autre. Le style d'un écrivain serait ce mouvement vers une autre énonciation. La nouvelle proposition pour la littérature du futur est donc axée sur le double procédé de déplacement et de mise à distance de l'expérience.

Inspired by the Six proposals de Ítalo Calvino this essay displays an additional one. On that purpose the author analyses the discursive modalities used by Rodolfo Walsh when he intends to communicate an event that seems impossible to be told. These modalities consist mainly in shifting the source of enunciation and delegating the experience to another's voice. The literary style of a writer could be this movement towards other enunciation, distant from one's own. The new proposal for future literature lies thus on that experience shifting enunciation process.

\section{ÍNDICE}

Mots-clés: propositions pour le prochain millénaire, Rodolfo Walsh, déplacement, énonciation, expérience

Keywords: proposals for the next millennium, shifting, enunciation

Palabras claves: propuestas para el próximo milenio, desplazamiento, enunciación, experiencia

\section{AUTOR}

\section{RICARDO PIGLIA}

Escritor 